\begin{tabular}{|l|c|c|c|c|c|}
\hline $\begin{array}{l}\text { Nereis. Revista Iberoamericana } \\
\text { Interdisciplinar de Métodos, } \\
\text { Modelización y Simulación }\end{array}$ & 13 & $135-146$ & $\begin{array}{c}\text { Universidad Católica de } \\
\text { Valencia San Vicente Mártir }\end{array}$ & $\begin{array}{c}\text { Valencia } \\
\text { (España) }\end{array}$ & ISSN 1888-8550 \\
\hline
\end{tabular}

\title{
Desechos de vinificación como inhibidores de biopelículas de Staphylococcus aureus
}

\author{
Wine-making wastes as biofilm inhibitors of Staphylococcus aureus
}

Fecha de recepción y aceptación: 17 de febrero de 2021 y 22 de abril de 2021

DOI: $10.46583 /$ nereis_2021.13.813

Carolina María Viola1, Elena Cartagena ${ }^{1,2}$ y Mario Eduardo Arena ${ }^{12^{* *}}$

${ }^{1}$ Instituto de Biotecnología Farmacéutica y Alimentaria (INBIOFAL). CONICET- Universidad Nacional de Tucumán.

${ }^{2}$ Facultad de Bioquímica, Química y Farmacia. Universidad Nacional de Tucumán.

* Correspondencia: Universidad Nacional de Tucumán. Facultad de Bioquímica, Química y Farmacia. Batalla de Ayacucho 471 - CPA

T4000INI. San Miguel de Tucumán. Tucumán. Argentina.E-mail: arename@fbqf.unt.edu.ar

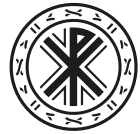

Universidad Católica de Valencia San Vicente Mártir

\section{RESUMEN}

Staphylococcus aureus es un patógeno conocido que forma biopelículas en una amplia variedad de entornos y representa un riesgo severo de contaminación de los alimentos. El presente estudio se centró en la determinación de las capacidades antibiofilm de extractos de orujo procedentes de diferentes varietales de diferentes polaridades, procedentes de Cafayate, Argentina, frente a dos cepas de $S$. aureus. Se utilizaron orujos de tres varietales regionales (Bonarda, Tannat y Malbec) para inhibir la formación de biofilm (BF) o tratar una biopelícula formada. Se realizaron extracciones con solventes de polaridad creciente (cloroformo, acetato de etilo y etanol) y se enfrentaron 10 y $100 \mu \mathrm{g} / \mathrm{mL}$ de extractos a las cepas de $S$. aureus ATCC 6538 y LVP63. Los extractos acetato de etilo y etanólicos de orujo del varietal Tannat fueron los más efectivos para disminuir la formación de $\mathrm{BF}$ en $S$. aureus sin afectar al crecimiento planctónico. Respecto a los efectos sobre la biopelícula preformada, los extractos de los varietales Malbec y Tannat disminuyeron la actividad metabólica hasta un $70 \%$ y los extractos polares de Tannat y la mezcla de orujos disgregaron hasta un $65 \%$ el BF preformado por ambas cepas $S$. aureus. Por lo tanto, la reutilización de estos desechos agroindustriales se plantea como una alternativa natural para combatir bacterias patógenas en la industria alimentaria, disminuyendo el impacto de estos residuos agroindustriales en el ambiente y convirtiendo a estos desechos en un bioproducto, económicamente, rentable.

PALABRAS CLAVE: biofilm, Staphylococcus aureus, orujo.

\section{ABSTRACT}

Staphylococcus aureus is a well-known pathogen living as biofilm in a wide variety of environments and represents a severe risk of food contamination. The present study focused on the antibiofilm capacity of pomace extracts of different polarities and different varietals against two strains of $S$. aureus. Wine pomace of three varietals (Bonarda, Tannat, and Malbec) from Cafayate, Argentine, at two concentrations (10 and $100 \mu \mathrm{g} / \mathrm{mL}$ ) was used to inhibit biofilm formation 
(BF) and preformed biofilm of S. aureus ATCC 6538 and LVP63 strains. Extractions were carried out with solvents of increasing polarity (chloroform, ethyl acetate, and ethanol). The ethyl acetate and ethanolic pomace extracts of the Tannat varietal were the most effective in reducing the BF formation in S. aureus without affecting planktonic growth. The extracts of Malbec and Tannat diminish the biofilm metabolic activity up to $70 \%$. Likewise, the polar Tannat extracts and the mixture pomace disrupt the preformed BF in both $S$. aureus strains.

These residues can be used as a natural alternative source for the inhibition of pathogenic bacteria in the food industry and reduce the impact of these agro-industrial wastes on the environment.

KEYWORDS: biofilm, Staphylococcus aureus, wine pomace.

\section{INTRODUCCIÓN}

Las bacterias son organismos sociales capaces de construir estructuras complejas, como biopelículas, que son comunidades de microorganismos altamente organizadas, incluidas en una matriz extracelular autoproducida y asociadas a una superficie [1].

Entre los principales microorganismos se encuentra Staphylococcus aureus, el cual es un patógeno capaz de formar biopelículas, tanto en superficies bióticas como abióticas de entornos clínicos y alimentarios, ganando una alta resistencia a los agentes antimicrobianos típicos, condiciones ambientales adversas e inmunidad del hospedador [2,3]. Este microorganismo se ha encontrado con frecuencia en las superficies de las plantas procesadoras de alimentos y es responsable de infecciones relacionadas con el consumo de alimentos frescos y procesados [4-6], así como también enfermedades de la piel, artritis séptica y endocarditis, entre otras [1].

El aumento de la incidencia de infecciones asociadas a $S$. aureus resistentes a los antibióticos requiere el desarrollo urgente de nuevas estrategias terapéuticas y fármacos antibacterianos [7].

Los productos naturales de plantas han demostrado ser eficaces como agentes antibiofilm, inhibiendo la formación de la matriz polimérica, suprimiendo la adhesión y unión celular y disminuyendo la producción de factores de virulencia, según la literatura [1].

Los residuos agroindustriales son una fuente natural de compuestos bioactivos y su uso reduce su acumulación y el impacto ambiental emergente [8]. En este contexto, la producción de vino es una actividad agroindustrial de alto valor económico mundial que genera cantidades considerables de desechos. Uno de ellos es el orujo, constituido por pieles, semillas y tallos y que representa, aproximadamente, el $20 \%$ del total de uvas procesadas [9-12]. Para reducir el impacto negativo de estos desechos en los ecosistemas, es necesario proponer usos alternativos. Los residuos de las bodegas constituyen productos naturales ricos en fitoquímicos (flavonoides, no flavonoides y taninos) con grandes oportunidades de utilización dada su estructura química y propiedades biológicas [12].

El presente estudio se centró en evaluar la capacidad antimicrobiana y antibiofilm de extractos de orujo, procedentes de diferentes varietales y de diferente polaridad frente a dos cepas de $S$. aureus. 


\section{METODOLOGÍA}

\section{Muestra y obtención de extractos}

Los desechos de la industria vitivinícola fueron orujos de tres variedades de uvas tintas: Bonarda, Tannat y Malbec, recolectados durante el año 2017 en Cafayate (Salta, Argentina).

Los residuos de vino presentaron consistencia blanda, húmeda, con colores característicos, según el varietal correspondiente.

La obtención de extractos con diferentes polaridades se llevó a cabo mediante la técnica de extracción sólido-liquido con solventes de polaridad creciente: cloroformo, acetato de etilo y etanol. Se efectuaron dos extracciones sucesivas por maceración. Posteriormente, los extractos obtenidos fueron filtrados y el solvente fue evaporado en evaporador rotatorio a presión reducida. Finalmente, se realizaron cálculos de rendimiento con respecto al peso del material procesado. De este modo, se obtuvieron los extractos clorofórmicos (EC), extractos de acetato de etilo (EA) y etanólico (EE). Además, se realizó la misma metodología de extracción para la mezcla industrial de orujos, cuya composición no fue declarada por la bodega y se obtuvo el extracto mezcla (MX). Para los ensayos los extractos se disuelven en una solución de DMSO.

\section{Cepas y condiciones de cultivo}

Las cepas fueron obtenidas de dos colecciones: Colección Americana de Cultivos Tipo (ATCC) y Laboratorio de Investigación de Valor Agregado de Productos Regionales y Alimentos (LVP) de INBIOFAL (Instituto de Biotecnología Farmacéutica y Alimentaria). Las cepas utilizadas fueron Staphylococcus aureus ATCC 6538 y Staphylococcus aureus LVP63, aislada de quesillo de Tafí del Valle de Tucumán cedido por la cátedra de Bacteriología de la Facultad de Bioquímica, Química y Farmacia de la UNT.

Las cepas fueron cultivadas en medio Müller-Hinton $(\mathrm{MH})$ (almidón 0,15\% p/V, infusión de carne, a partir de $300 \mathrm{~g}, 0,2 \% \mathrm{p} / \mathrm{V}$, peptona de caseína hidrolizada $1,75 \% \mathrm{p} / \mathrm{V}, \mathrm{pH}$ 7,4 y esterilización en autoclave a $1 \mathrm{~atm})$.

\section{Crecimiento bacteriano}

A partir de un cultivo overnight de la cepa en estudio en el medio de cultivo correspondiente, se realizaron diluciones hasta alcanzar una DO de $0,1\left(1 \times 10^{8} \mathrm{UFC} / \mathrm{mL}\right)$ y se sembraron $195 \mu \mathrm{L}$ en cada pocillo de una microplaca. A continuación, se sembraron $5 \mu \mathrm{L}$ de cada una de las soluciones de los extractos, preparadas anteriormente, de manera que se alcanzaron concentraciones finales de 100 $\mu \mathrm{g} / \mathrm{mL}$ y $10 \mu \mathrm{g} / \mathrm{mL}$. Como control positivo de crecimiento bacteriano, se utilizó el medio de cultivo fresco sembrado con la cepa en estudio y adicionado con $5 \mu \mathrm{L}$ de DMSO (que corresponde a una concentración del 2,5\%, la cual no inhibe el crecimiento ni la formación del biofilm bacteriano). El control negativo de crecimiento empleado fue ciprofloxacina, un antibiótico perteneciente al grupo 
de las fluoroquinolonas en una concentración de $5 \mu \mathrm{g} / \mathrm{mL}$. El crecimiento bacteriano se monitoreó a $560 \mathrm{~nm}$ en microplacas de poliestireno, usando un lector espectrofotométrico de microplacas ( $\mathrm{Mul}$ tiskanGo, Thermo) a una temperatura de $37^{\circ} \mathrm{C}$, durante $24 \mathrm{~h}$. Cada una de las concentraciones de los extractos se ensayó en siete repeticiones y el bioensayo se realizó por duplicado.

\section{Formación de biofilm bacteriano}

Para la cuantificación de biofilm (BF) se utilizó un método colorimétrico de revelado de microplaca, basado en un protocolo descrito previamente [13]. En este trabajo, se cuantificó biomasa de la biopelícula a las $24 \mathrm{~h}$, empleando una solución de cristal violeta $(0,1 \%)$ con modificaciones [14, 15$]$.

Después de 24 h de incubación, el sobrenadante fue descartado y se agregaron $200 \mu \mathrm{L}$ de solución de cristal violeta a cada de uno de los pocillos. Luego se incubó de manera estática durante $30 \mathrm{~min}$. Como el BF tiene afinidad por el poliestireno y queda retenido en las paredes de los pocillos, se lavó la microplaca con agua destilada, descartando así el cultivo no adherido y el exceso de colorante. Teniendo en cuenta la mayor solubilidad del cristal violeta en etanol se agregaron $200 \mu \mathrm{L}$ de etanol absoluto, con agitación suave a $37^{\circ} \mathrm{C}$, durante $30 \mathrm{~min}$. La absorbancia se midió a $595 \mathrm{~nm}$. La inhibición de la biopelícula se calculó mediante la siguiente fórmula:

Porcentaje de inhibición del BF = 100- [(OD595 nm con extracto x 100/OD595 nm de control]

\section{Disrupción del biofilm bacteriano}

El efecto de los extractos en un BF previamente formado, se realizó de acuerdo a la técnica de Baker y colaboradores (2016), con algunas modificaciones [16].

En una microplaca de poliestireno de 96 pocillos, se sembró un cultivo bacteriano overnight de la cepa en estudio, al que se realizó la dilución correspondiente para alcanzar una DO de 0,1 y se incubó a $37{ }^{\circ} \mathrm{C}$ durante $24 \mathrm{~h}$. Se descartó el sobrenadante y se lavó con agua destilada estéril, excluyendo el BF no adherido al poliestireno. A continuación, se adicionaron sobre el BF formado $5 \mu \mathrm{L}$ de la solución del extracto analizado y $195 \mu \mathrm{L}$ de buffer PBS estéril. Se incubó a $37^{\circ} \mathrm{C}$, durante 24 h. Posteriormente, el sobrenadante se eliminó, se lavó con agua destilada y se adicionaron $200 \mu \mathrm{L}$ de una solución de cristal violeta $(0,1 \%)$, para teñir el BF presente. Se incubó de manera estática durante 30 minutos y luego se agregaron $200 \mu \mathrm{L}$ de etanol absoluto con agitación suave a $37^{\circ} \mathrm{C}$, durante 30 minutos. Finalmente, se midió la absorbancia a $595 \mathrm{~nm}$.

En este bioensayo se utilizaron los mismos controles que en el ensayo de formación del biofilm bacteriano.

\section{Actividad metabólica de células bacterianas en biofilms}

La actividad metabólica de las bacterias en BF se evaluó usando el ensayo de reducción del bromuro de 3-(4,5-dimetiltiazol-2-ilo)-2,5-difeniltetrazol (MTT) con algunas modificaciones [17,18]. A 
partir de un cultivo bacteriano overnight, se realizó la dilución correspondiente hasta alcanzar una DO de 0,1 . Posteriormente, se sembraron $200 \mu \mathrm{L}$ de este en una microplaca de poliestireno de 96 pocillos y se incubó a $37^{\circ} \mathrm{C}$ durante $24 \mathrm{~h}$. A continuación, los sobrenadantes se descartaron y la microplaca se lavó con buffer PBS estéril, para eliminar restos del BF que no se hubiera adherido al plástico. Se adicionaron $5 \mu \mathrm{L}$ de cada una de las soluciones de los extractos que ensayar y $195 \mu \mathrm{L}$ de la solución de PBS estéril. Por consiguiente, las microplacas de poliestireno se incubaron a $37^{\circ} \mathrm{C}$, durante $24 \mathrm{~h}$. Luego se descartó el sobrenadante y se adicionaron volúmenes iguales de MTT $(0,5 \mathrm{mg} / \mathrm{mL})$ y buffer PBS. Se incubó a $37^{\circ} \mathrm{C}$ durante $5 \mathrm{~h}$, se descartó el medio y se lavó con PBS. Por último, el púrpura de formazán, obtenido por hidrólisis enzimática del MTT (por células viables), fue disuelto con DMSO y la absorbancia se midió a $570 \mathrm{~nm}$, usando un lector de microplacas.

\section{RESULTADOS}

\section{Crecimiento y formación de biofilm}

El efecto de los extractos de orujo de vino tinto en el crecimiento y la formación del biofilm de la cepa $S$. aureus ATCC 6538 se observa en la figura 1 . Se deduce que la formación del biofilm bacteriano fue inhibida por todos los extractos de orujos de vino tinto a las dos concentraciones ensayadas. Los extractos más activos fueron los del varietal Tannat, con inhibiciones del 61-72\%, a las concentraciones del ensayo (10 y $100 \mu \mathrm{g} / \mathrm{mL}$ ). Mientras que los extractos del varietal Malbec inhibieron la formación de la biopelícula entre un $51-70 \%$, a $100 \mu \mathrm{g} / \mathrm{mL}$.

En la cepa contaminante de queso, S. aureus LVP63, todos los extractos de orujo de vino tinto fueron capaces de inhibir la formación de la biopelícula bacteriana a la mayor concentración ensayada, inhibiendo entre un 40 y un $70 \%$ (figura 2). Es importante destacar que los extractos acetato de etilo y etanólico del varietal Tannat redujeron notablemente la formación de la biopelícula entre un 67-77\%, tanto a $10 \mu \mathrm{g} / \mathrm{mL}$ como a $100 \mu \mathrm{g} / \mathrm{mL}$.

De acuerdo con las figuras 1 y 2 , los extractos de orujo de vino tinto a las concentraciones ensayadas no afectaron al crecimiento bacteriano.

La relación entre la producción de biofilm y el crecimiento bacteriano, denominado biofilm específico, indica la cantidad de biofilm que forma cada bacteria [19]. Bajo idénticas condiciones experimentales, la producción específica de la biopelícula por ambas cepas fue afectada por los extractos obtenidos. En S. aureus ATCC 6538, el biofilm específico fue disminuido 5 veces por los extractos acetato de etilo y etanólico de Tannat $(0,27$ y 0,28 , respectivamente), en relación con el control bacteriano $(1,30)$. Mientras que el extracto Malbec acetato de etilo (M EA) redujo el biofilm específico $(0,38)$, aproximadamente, 3,4 veces respecto al control. En la cepa salvaje de S. aureus LVP63 el efecto de los extractos acetato de etilo y etanólico de Tannat fue similar a la cepa de referencia, disminuyendo el biofilm específico de 0,81 (control) a 0,23 y 0,21 a $100 \mu \mathrm{g} / \mathrm{mL}$, respectivamente. 
Crecimiento y formación del biofilm de Staphylococcus aureus ATCC 6538

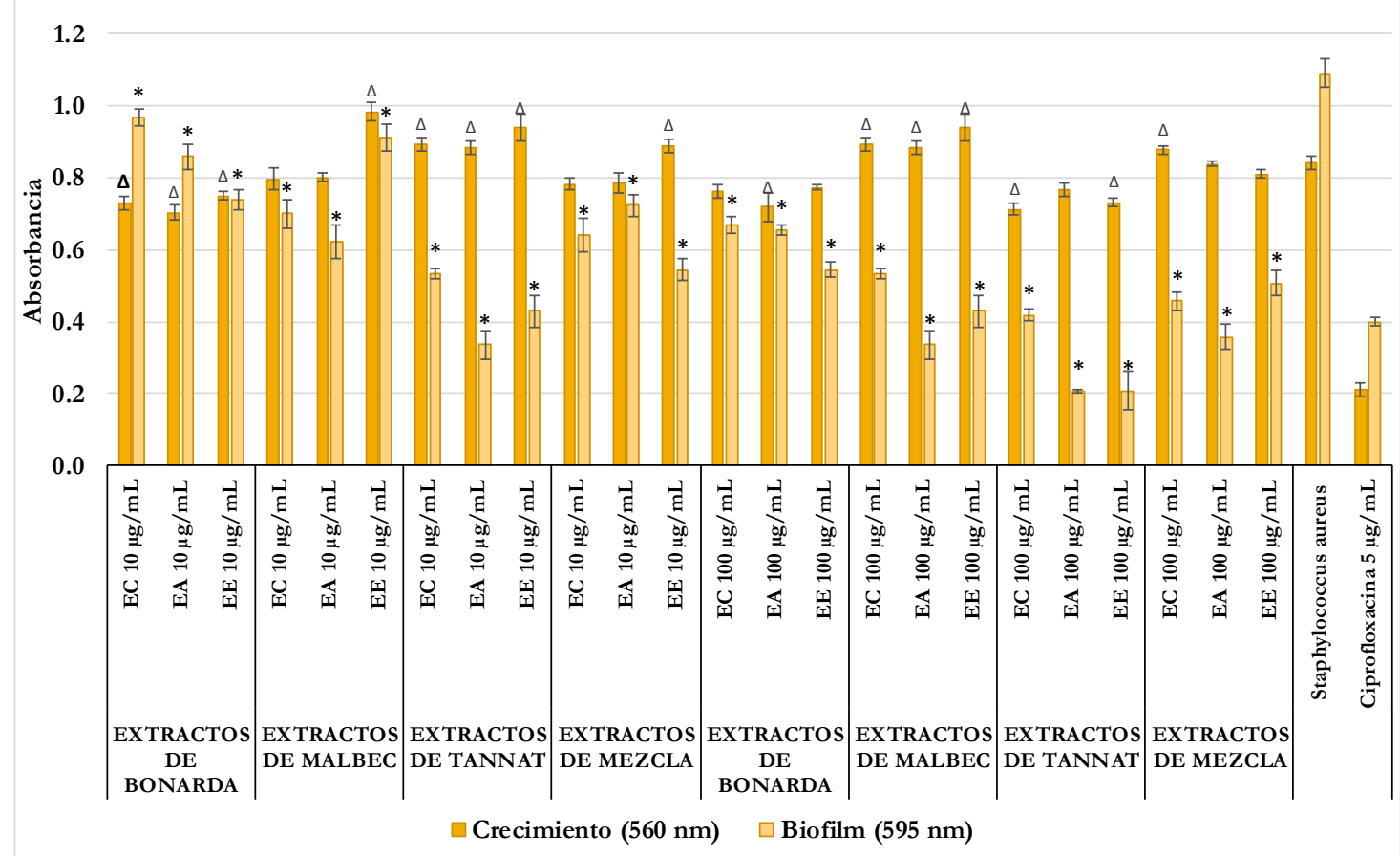

Fig. 1. Efecto de los extractos de orujo $(10 \mu \mathrm{g} / \mathrm{mL}$ y $100 \mu \mathrm{g} / \mathrm{mL})$ en el crecimiento y formación de biofilm de Staphylococcus aureus ATCC 6538. EC: extracto clorofórmico, EA: extracto de acetato de etilo, EE: extracto etanólico.

Control negativo: ciprofloxacina $(5 \mu \mathrm{g} / \mathrm{mL})$. Los valores representan los promedios de las medidas realizadas $(n=7)$. $(\Delta)$ Indica las muestras que son significativamente diferentes al control de crecimiento de la cepa. $\left.{ }^{*}\right)$ Indica las muestras que presentan diferencias significativas con el control de formación de biofilm $(p<0,05)$. La estadística se realizó por ANOVA, seguido del test de Tukey $(p<0,05)$. 


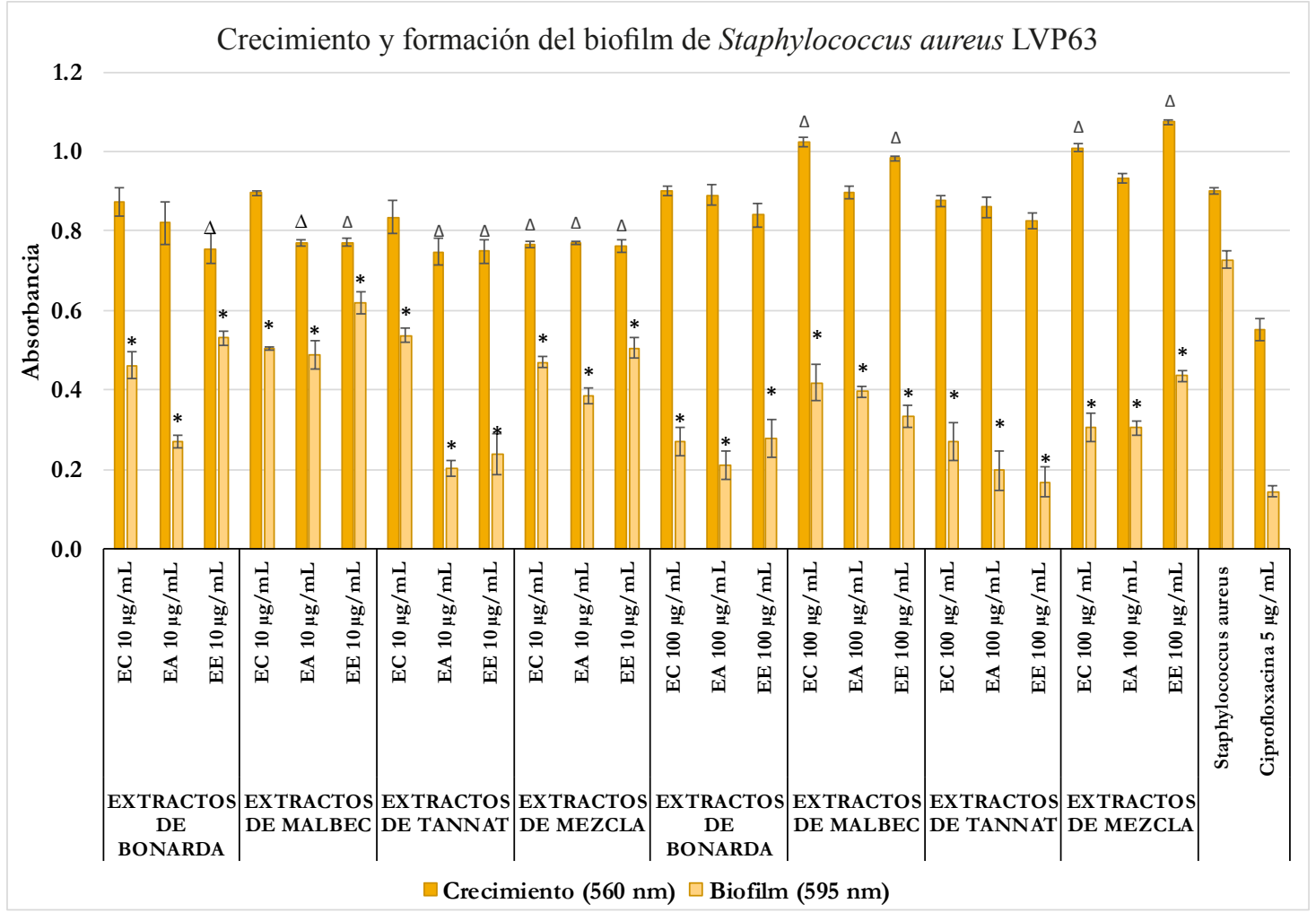

Fig.2. Efecto de los extractos de orujo $(10 \mu \mathrm{g} / \mathrm{mL}$ y $100 \mu \mathrm{g} / \mathrm{mL})$ en el crecimiento y formación de biofilm de Staphylococcus aureus LVP63. EC: extracto clorofórmico, EA: extracto de acetato de etilo, EE: extracto etanólico. Control negativo: ciprofloxacina $(5 \mu \mathrm{g} / \mathrm{mL})$. Los valores representan los promedios de las medidas realizadas $(n=7) .(\Delta)$ Indica las muestras que son significativamente diferentes al control de crecimiento de la cepa. $(*)$ Indica las muestras que presentan diferencias significativas con el control de formación de biofilm $(p<0,05)$. La estadística se realizó por ANOVA, seguido del test de Tukey $(p<0,05)$.

En relación con los efectos disruptores de un biofilm maduro de S. aureus ATCC 6538, los extractos acetato de etilo y etanólico del varietal Tannat a $100 \mu \mathrm{g} / \mathrm{mL}$ produjeron una disgregación del $48 \%$ y $65 \%$, respectivamente. Asimismo, la cepa LVP63 fue muy sensible a la acción de los extractos acetato de etilo y etanólico del varietal Tannat y la mezcla de orujos, los cuales disrumpieron la biopelícula bacteriana entre un $41 \%$ y un $65 \%$, a las concentraciones del ensayo.

De acuerdo con las figuras 3 y 4 , la actividad metabólica de las cepas de $S$. aureus fue disminuida entre un $43 \%$ y un $70 \%$ por los extractos acetato de etilo y etanólicos de orujos de vino, a la mayor concentración ensayada. El extracto con mayor porcentaje de inhibición para reducir la viabilidad celular de $S$. aureus ATCC 6538 fue M EA $(100 \mu \mathrm{g} / \mathrm{mL})$ con un $70 \%$. Mientras que, en la cepa contaminante, los extractos más polares de los varietales Tannat y Malbec inhibieron el metabolismo celular entre un $51 \%$ y un $64 \%$, a las concentraciones ensayadas. 
Actividad metabólica y disrupción del biofilm maduro de Staphylococcus aureus ATCC 6535

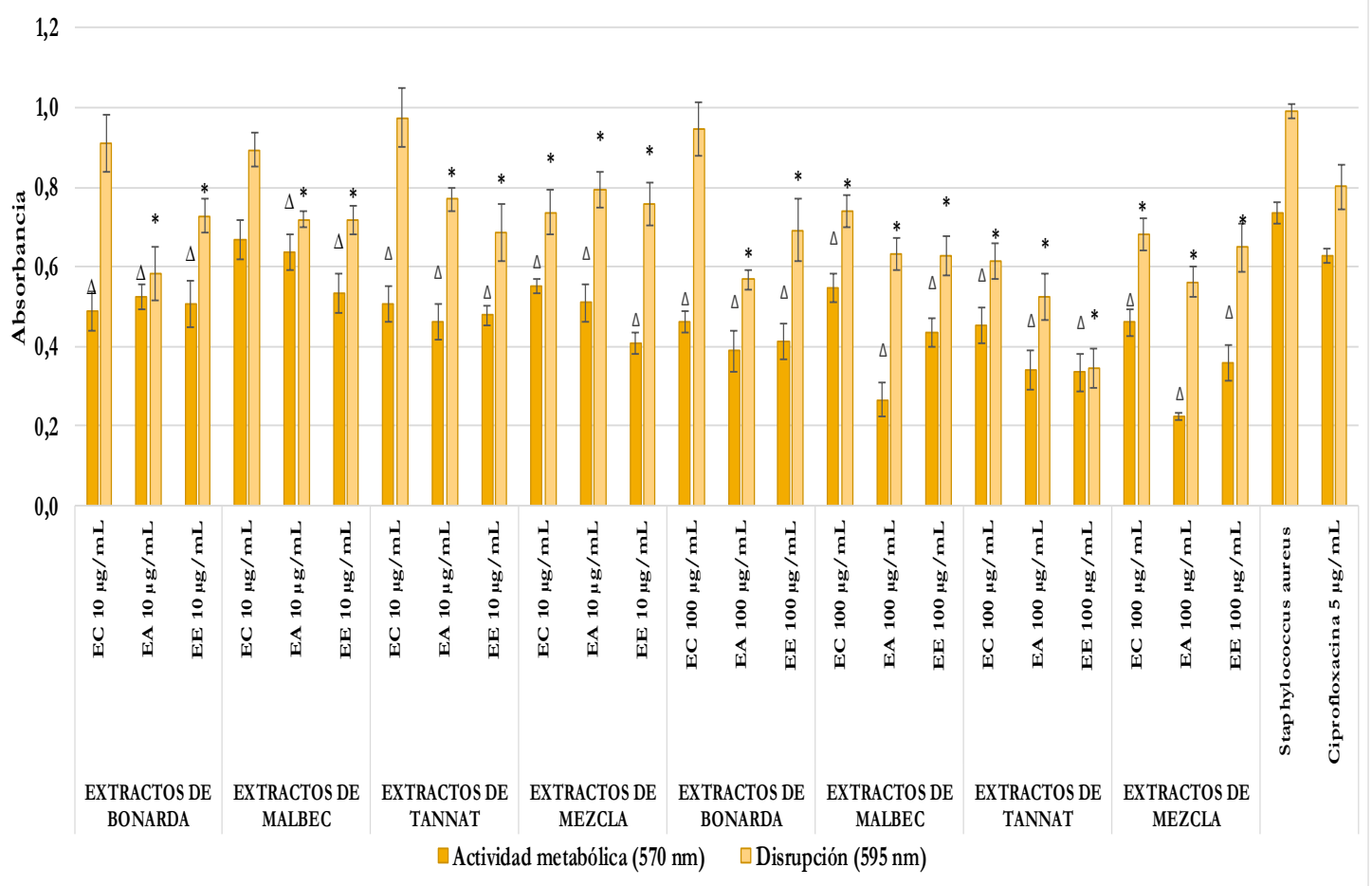

Fig. 3. Capacidad disruptora e inhibición de la actividad metabólica del biofilm de Staphylococcus aureus ATCC 6538 de los extractos de orujo (10 $\mu \mathrm{g} / \mathrm{mL}$ y $100 \mu \mathrm{g} / \mathrm{mL})$. EC: extracto clorofórmico, EA: extracto de acetato de etilo, EE: extracto etanólico. Control negativo: ciprofloxacina $(5 \mu \mathrm{g} / \mathrm{mL})$. Los valores representan los promedios de las medidas realizadas $(n=7)$. $(\Delta)$ Indica las muestras que son significativamente diferentes al control de actividad metabólica. $(*)$ Indica las muestras que presentan diferencias significativas $(p<0,05)$ respecto al control de la cepa. La estadística se realizó por ANOVA, seguido del test de Tukey $(p<0,05)$. 


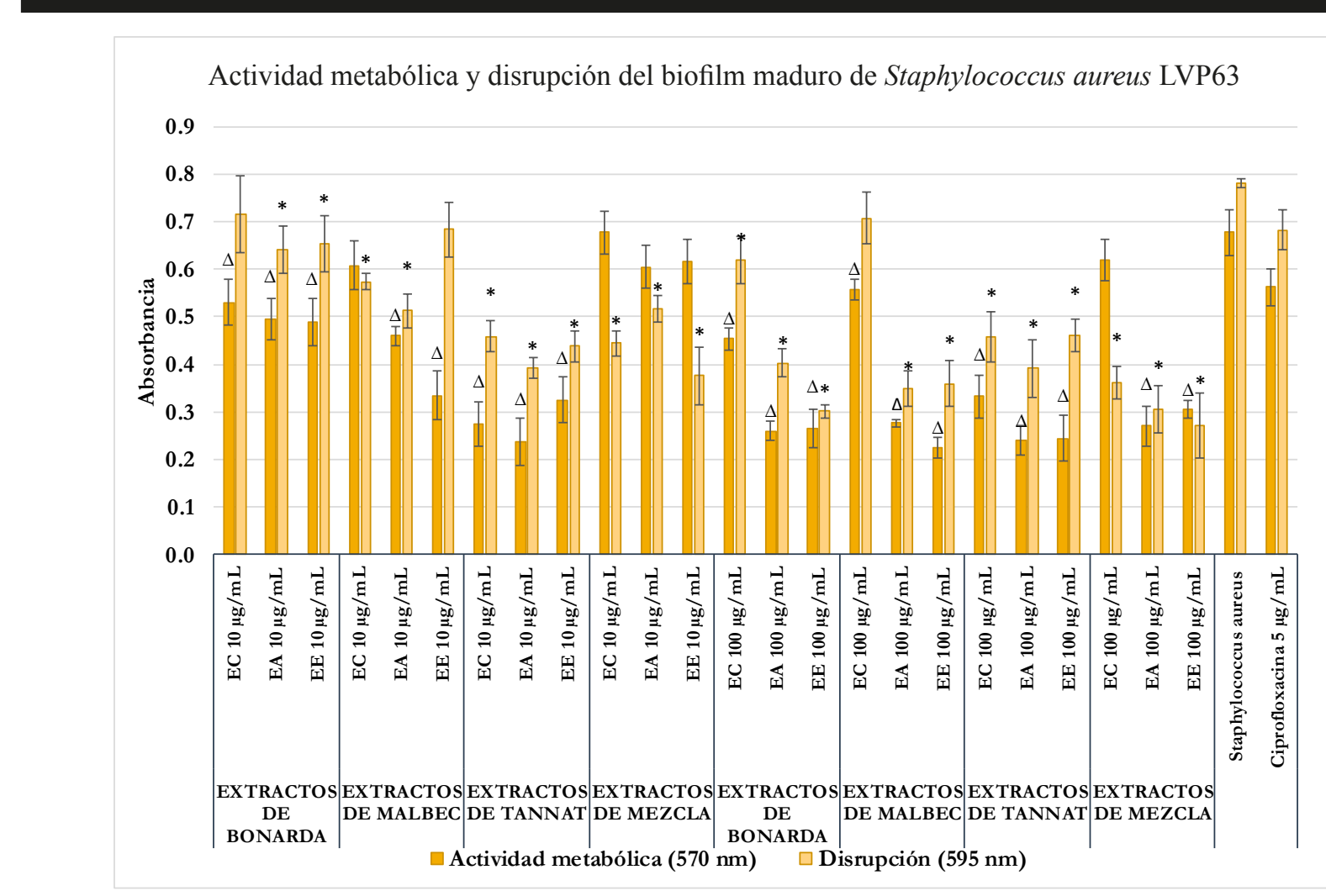

Fig. 4. Capacidad disruptora e inhibición de la actividad metabólica del biofilm de Staphylococcus aureus LVP63 de los extractos de orujo $(10 \mu \mathrm{g} / \mathrm{mL}$ y $100 \mu \mathrm{g} / \mathrm{mL})$. EC: extracto clorofórmico, EA: extracto de acetato de etilo, EE: extracto etanólico. Control negativo: ciprofloxacina $(5 \mu \mathrm{g} / \mathrm{mL})$. Los valores representan los promedios de las medidas realizadas $(n=7)$. ( $\Delta)$ Indica las muestras que son significativamente diferentes al control de actividad metabólica. (*) Indica las muestras que presentan diferencias significativas $(p<0,05)$ respecto al control de la cepa. La estadística se realizó por ANOVA, seguido del test de Tukey $(p<0,05)$.

\section{DISCUSIÓN}

Los residuos generados por las bodegas son ricos en compuestos fenólicos con propiedades antioxidantes y antibacterianas que contribuyen a la fitotoxicidad, haciendo limitado su uso inmediato para medios agrícolas [20]. En la búsqueda de nuevos fármacos y enfoques alternativos para el tratamiento de infecciones relacionadas con biopelículas, los extractos naturales y los agentes antibiofilm a base de productos naturales, como los desechos de la bodega, resultan una estrategia prometedora. Los fitoquímicos presentes en los orujos actúan en las diferentes etapas del desarrollo de la biopelícula e inducen la inactivación y eliminación de la biopelícula mediante su debilitamiento, dispersión o disrupción [21].

El contenido fenólico del vino y, por ende, de sus desechos, depende del contenido fenólico de la uva, el cual puede variar en diferentes cultivares, dependiendo de la ubicación geográfica, el tiempo de cosecha y el ambiente de crecimiento de la vid (agua y nutriente, luz y temperatura). 
En este trabajo los extractos acetato de etilo y etanólicos de orujo de tres varietales regionales fueron efectivos para disminuir la formación de $\mathrm{BF}$ en $S$. aureus sin afectar al crecimiento planctónico a las concentraciones de 10 y $100 \mu \mathrm{g} / \mathrm{mL}$. El efecto de los extractos del varietal Tannat fue mayor que los demás extractos en ambas concentraciones. Respecto a los efectos sobre la biopelícula preformada en poliestireno, la actividad metabólica de las células en biofilms de las cepas Gram positivas fue disminuida por los extractos de los varietales Malbec y Tannat hasta un $70 \%$. A su vez, los extractos acetato de etilo y etanólico de Tannat y la mezcla de orujos disgregaron la biopelícula preformada en ambas cepas de $S$. aureus, alcanzando una disgregación de un $65 \%$ de esta.

La actividad antibacteriana y antioxidante de extractos de orujo de vino tinto contra bacterias Gram positivas y Gram negativas está ampliamente investigada [22-24]. Olejar et al. (2019) reportaron que el extracto acuoso de orujo de uva mostró actividad antibacteriana contra $S$. aureus y Escherichia coli a $1,25 \mathrm{mg} / \mathrm{ml}$ y $20 \mathrm{mg} / \mathrm{ml}$ respectivamente, siendo las concentraciones ensayadas por los autores mucho mayores respecto a las utilizadas en este trabajo [20].

En este estudio fueron importantes los efectos de los extractos del varietal Tannat, del cual se sabe que contienen altas cantidades de taninos. Yang et al. (2016) encontraron que fracciones tánicas de extractos naturales de Terminalia catappa fueron efectivas para inhibir biopelículas bacterianas en concentraciones subinhibitorias [25]. También se informó que el ácido tánico en concentraciones mayores a $100 \mu \mathrm{g} / \mathrm{mL}$ tiene actividad antibacteriana contra $S$. aureus y a $20 \mu \mathrm{M}$ (correspondiente a $34 \mu \mathrm{g} / \mathrm{mL}$ ) inhibe la formación de biopelículas de $S$. aureus [26-28]. Dong et al. (2017) demostraron que el ácido tánico inhibe la formación de biopelículas de $S$. aureus a concentraciones sub-MIC, y proponen como mecanismo de acción que el ácido tánico pueda unirse directamente al peptidoglicano de la pared celular e interferir con su integridad y así inhibir la formación de biopelículas en S. aureus. No obstante, aún se requieren más estudios para identificar los mecanismos de acción subyacentes del ácido tánico [29].

En este estudio los resultados obtenidos indican que los extractos de orujo de vino tinto tienen la capacidad de reducir la biomasa de las biopelículas formadas así como también la actividad metabólica de un biofilm preformado, a diferencia de otros informes en los que reportaron que productos naturales afectaban a la actividad metabólica en mayor medida que la reducción de la biomasa de las biopelículas de $S$. aureus resistente a meticilina [30].

\section{CONCLUSIONES}

Los desechos agroindustriales utilizados en este trabajo inhibieron la formación de biopelículas, lo cual determina un efecto protector o preventivo de estos bioproductos frente a este factor de virulencia. Más importante aún es que puede disrumpir un biofilm previamente formado, disminuyendo la cantidad total de biopelícula y la actividad metabólica de las bacterias que conforman el biofilm en $S$. aureus. La capacidad de eliminar una contaminación ya establecida, por la formación de una biopelícula, permite inferir un gran potencial como desinfectante natural para estos extractos.

Por lo tanto, la utilización de estos desechos se plantea como una alternativa natural para combatir bacterias patógenas en la industria alimentaria, disminuyendo el impacto de estos residuos agroindustriales en el medio ambiente y convirtiendo a estos desechos en un bioproducto económicamente rentable. 


\section{REFERENCIAS BIBLIOGRÁFICAS}

[1] Guzzo F, Scognamiglio M, Fiorentino A, Buommino E, D'abrosca B, Marcotullio MC. Plant Derived Natural Products against Pseudomonas aeruginosa and Staphylococcus aureus: Antibiofilm Activity and Molecular Mechanisms. Molecules. 2020;25(21):5024.

[2] Li XH, Lee JH. Antibiofilm agents: A new perspective for antimicrobial strategy. J of Microbiol. 2017;55(10):753-766.

[3] Cha Y, Son B, Ryu S. Effective removal of staphylococcal biofilms on various food contact surfaces by Staphylococcus aureus phage endolysin LysCSA13. Food microbiol. 2019;84:103245.

[4] Doulgeraki A, Ciccio P Di. Methicillin-resistant food-related Staphylococcus aureus: a review of current knowledge and biofilm formation for future studies and applications. Microbiol. Res. 2017;168(1):1-15.

[5] Blando F, Russo R, Negro C, De Bellis L, Frassinetti S. Antimicrobial and antibiofilm activity against Staphylococcus aureus of Opuntia ficus-indica (L.) mill. cladode polyphenolic extracts. Antioxidants. 2019;8(5).

[6] Miao J, Lin S, Soteyome T, Peters BM, Li Y, Chen H, et al. Biofilm Formation of Staphylococcus aureus under Food Heat Processing Conditions: First Report on CML Production within Biofilm. Sci Rep. 2019;9(1):1-9.

[7] Shuai-Cheng W, Liu F, Zhu K, Wu S-C, Shen J-Z. Natural products that target virulence factors in antibiotic-resistant Staphylococcus aureus. Artic J Agric Food Chem. 2019;67(48):13195211.

[8] Kowalska H, Czajkowska K, Cichowska J, Lenart A. What's new in biopotential of fruit and vegetable by-products applied in the food processing industry. Trends Food Sci Technol. 2017;67:150-9.

[9] Mora F, Pérez K, Quezada C, Herrera C, Cassano A, Ruby-Figueroa R. Impact of membrane pore size on the clarification performance of grape marc extract by microfiltration. Membranes 2019;9(11):146.

[10] Ianni A, Luca A Di, Martino C, Bennato F, Marone E, Grotta L, et al. Dietary supplementation of dried grape pomace increases the amount of linoleic acid in beef, reduces the lipid oxidation and modifies the volatile profile. Animals. 2019;9:578.

[11] Bennato F, Luca A Di, Martino C, Ianni A, Marone E, Grotta L, et al. Influence of grape pomace intake on nutritional value, lipid oxidation and volatile profile of poultry meat. Foods. 2020;9(4).

[12] Portilla Rivera OM, Saavedra Leos MD, Solis VE, Domínguez JM. Recent trends on the valorization of winemaking industry wastes. Curr Opin Green Sustain Chem. 2020;100415.

[13] O'Toole GA, Kolter R. Initiation of biofilm formation in Pseudomonas fluorescens WCS365 proceeds via multiple, convergent signalling pathways: a genetic analysis. Mol Microbiol. 1998;28(3):449-61.

[14] Luciardi MC, Blázquez MA, Cartagena E, Bardón A, Arena ME. Mandarin essential oils inhibit Quorum sensing and virulence factors of Pseudomonas aeruginosa. LWT - Food Sci Technol. 2016;68:373-80. 
[15] D’Almeida RE, Molina RRDI, Viola CM, Luciardi MC, Nieto Peñalver C, Bardón A, et al. Comparison of seven structurally related coumarins on the inhibition of Quorum sensing of Pseudomonas aeruginosa and Chromobacterium violaceum. Bioorg Chem. 2017;73:37-42.

[16] Baker P, Hill PJ, Snarr BD, Alnabelseya N, Pestrak MJ, Lee MJ, et al. Exopolysaccharide biosynthetic glycoside hydrolases can be utilized to disrupt and prevent Pseudomonas aeruginosa biofilms. Sci Adv. 2016;2(5):1-10.

[17] Schillaci D, Arizza V, Dayton T, Camarda L, Stefano VD. In vitro anti-biofilm activity of Boswellia spp. oleogum resin essential oils. Lett Appl Microbiol. 2008;47(5):433-8.

[18] Jadhav S, Shah R, Bhave M, Palombo EA. Inhibitory activity of yarrow essential oil on Listeria planktonic cells and biofilms. Food Control. 2013;29(1):125-30.

[19] Amaya S, Pereira JA, Borkosky SA, Valdez JC, Bardón A, Arena ME. Inhibition of quorum sensing in Pseudomonas aeruginosa by sesquiterpene lactones. Phytomedicine. 2012;19(13):11737.

[20] Olejar KJ, Ricci A, Swift S, Zujovic Z, Gordon KC, Fedrizzi B, et al. Characterization of an antioxidant and antimicrobial extract from cool climate, white grape marc. Antioxidants. 2019;8(7):1-13.21.

[21] Mishra R, Panda AK, De Mandal S, Shakeel M, Bisht SS, Khan J. Natural anti-biofilm agents: strategies to control biofilm-forming pathogens. Front Microbiol. 2020;11.

[22] Teixeira A, Baenas N, Dominguez-Perles R, Barros A, Rosa E, Moreno D, et al. Natural bioactive compounds from winery by-products as health promoters: a review. Int J Mol Sci. 2014;15(9):15638-78.

[23] Domínguez-Perles R, Guedes A, Queiroz M, Silva AM, Barros AIRNA. Oxidative stress prevention and anti-apoptosis activity of grape (Vitis vinifera L.) stems in human keratinocytes. Food Res Int. 2016;87:92-102.

[24] Vázquez-Armenta FJ, Silva-Espinoza BA, Cruz-Valenzuela MR, González-Aguilar GA, Nazzaro F, Fratianni F, et al. Antibacterial and antioxidant properties of grape stem extract applied as disinfectant in fresh leafy vegetables. J Food Sci Technol. 2017;54(10):3192-200.

[25] Yang Q, Wang L, Gao J, Liu X, Feng Y, Wu Q, et al. Tannin-rich fraction from pomegranate rind inhibits Quorum sensing in Chromobacterium violaceum and biofilm formation in Escherichia coli. Foodborne Pathog Dis. 2016;13(1):28-35.

[26] Payne DE, Martin NR, Parzych KR, Rickard AH, Underwood A, Boles BR. Tannic acid inhibits Staphylococcus aureus surface colonization in an isaa-dependent manner. Infect Imm. 2013;81(2):496-504.

[27] Lee JH, Park JH, Cho HS, Joo SW, Cho MH, Lee J. Anti-biofilm activities of quercetin and tannic acid against Staphylococcus aureus. Biofouling. 2013;29(5):491-9.

[28] Cho HS, Lee JH, Cho MH, Lee J. Red wines and flavonoids diminish Staphylococcus aureus virulence with anti-biofilm and anti-hemolytic activities. Biofouling. 2015;31(1):37-41.

[29] Dong G, Liu H, Yu X, Zhang X, Lu H, Zhou T, et al. Antimicrobial and anti-biofilm activity of tannic acid against Staphylococcus aureus. Nat. Prod. Res. 2017;32(18):2225-8.

[30] Kot B, Wierzchowska K, Grużewska A, Lohinau D. The effects of selected phytochemicals on biofilm formed by five methicillin-resistant Staphylococcus aureus. Nat Prod Res. 2018;32(11):1299-302. 